\title{
Semantic priming effects and lexical access in English as L3
}

Pâmela Freitas Pereira Toassi ${ }^{a}$

Mailce Borges Mota ${ }^{b}$

\section{Resumo}

We report an experiment using a picturenaming task within the masked priming paradigm to examine lexical access in English as a third language. Participants were assigned to one of three groups: a control group, consisting of native speakers of English, and two experimental groups, one consisting of speakers of English as L2 and the other consisting of speakers of German as L2 and English as L3. Participants of the two experimental groups were native speakers of Brazilian Portuguese. All participants performed a picture-naming task in English in which pictures were preceded by a masked prime word in the target language (English), in the native language (Brazilian Portuguese) or in the second language (German). The results indicate some interference from the participants' second language in the production of their third language (English), favoring the view that lexical access of multilinguals is qualitatively different from that of bilinguals and monolinguals.

Keywords: lexical access, multilinguals, priming effect, picture-naming task.

Recebido em: 09/05/2018 Aceito em: 12/07/2018

\footnotetext{
a Departamento de Estudos da Língua Inglesa, suas Literaturas e Tradução da Universidade Federal do Ceará. E-mail: pam.toassi@gmail.com.

${ }^{\mathrm{b}}$ Departamento de Língua e Literatura Estrangeiras da Universidade Federal de Santa Catarina. E-mail: mailcemota54@gmail.com.
} 


\section{Introduction}

Speaking seems to be a simple task in our daily lives. However, the effortless and automatized cognitive activity of uttering words requires a series of complex mechanisms for its accomplishment. The process of lexical access, that is, the search for a word, or the match between a word and its corresponding meaning, is fast, automatic and effective most of the time. However, many variables may interfere with this process, especially when the multilingual lexicon is concerned. The social context, the number of languages spoken, the similarity among the two, three or more languages, the proficiency level in each language, and the frequency of use of each language involved are some of the factors that may affect lexical access processes in bilinguals and multilinguals (SZUBKO-SITAREK, 2015).

In bilingual or multilingual language production, it is not unusual to experience difficulties in the retrieval of a specific word in a conversation. Ecke (2015) explains two phenomena related to the failure of lexical retrieval: (1) intrusions that lead to lexical replacements or to the blending of two or more lexical forms, and (2) lexical errors that occur when there is difficulty in retrieving the target word. According to Ecke (2015), investigating these difficulties in lexical retrieval might shed light on the processes involved in lexical access during language production.

Failure of lexical retrieval may occur in the native as well as in the nonnative languages. However, in the L2, L3 or Ln, ${ }_{1}$ which might be non-dominant languages, failures in lexical retrieval might be even more common. In cases of failure of

${ }^{1}$ In the present study, the term L1 will be used to refer to the native language. The term L2 will be used interchangeably to refer to both foreign or second language and the term L3 will be used to refer to third language. In addition, the term bilingualism will be used to refer to the use of 2 languages, whereas the term multilingualism will be used to refer to the use of 3 or more languages. lexical retrieval in the L2, it is possible that a word in the L1 will be more easily accessed than its translation in the L2. This phenomenon is called crosslinguistic influence, that is, the influence that one language causes in the processing of another (JESSNER, 2003).

In bilingual processing, many factors constrain the retrieval of words, including the level of activation of the languages (dormant languages may be harder to access than dominant languages) and the cognate status of the words (cognate words may be easier to access than noncognate words). For multilinguals, the process of lexical access can 
become more complex than for bilinguals and monolinguals, due to the greater possibilities of language influence and/or interference. That is, for multilinguals there are more sources of crosslinguistic influences. For a trilingual, during lexical access of the L3, there can be influence of both L1 and L2 (HAMMARBERG, 2001; VINNITSKAYA; FLYNN; FOLEY, 2002; LEUNG, 2005; HARTSUIKER et al., 2016). There is also evidence of the influence of a foreign language (L2) in the processing of the native language (L1) (SOUZA; OLIVEIRA, 2011; SOUZA, 2012).

The influence of the non-target languages in lexical access may depend on the strength of the connections between the representations of the lexical and conceptual levels among the languages (SZUBKO-SITAREK, 2015), the lexical level being related to language forms, and the conceptual level, to word meaning. There are some factors that constrain the availability of the lexical/conceptual connections between the bilinguals' two languages or the multilinguals' several languages. These factors might be related to the similarity among the languages, or more specifically, among the words of the different languages at the orthographic, phonological or semantic levels, for instance. In addition, context may play a role in lexical access, level of proficiency, and relationship between the languages. For instance, the relation nativenonnative language might be seen as dominant versus nondominant language. In this case, the role of the L1 must be analyzed. According to Kroll (1993):

For adults who already have a fluent and dominant first language, and for whom the second language is acquired within the cultural context of the first language, the problem is not to learn new concepts, but rather to acquire new mappings between concepts and second language words. Changes in the development of those mappings as second language learners become increasingly fluent in the second language may reveal important constraints for theories of lexical and semantic memory (KROLL, 1993, p. 55).

In the present study, the issue under investigation lies in the scenario described by Kroll (1993), in that participants have a dominant L1 (Brazilian Portuguese) and have learned the second languages (German or English) in the environment of this L1. Our aim was to investigate lexical access processes in 
the production of nonnative speakers of English who also have knowledge of Brazilian Portuguese as the L1 and of German as the L2. Our contention is that trilingual lexical access is qualitatively different from bilingual and monolingual lexical access. That is, the number of languages one is able to use has implications for lexical organization and access.

\section{Lexical access in bilinguals and multilinguals}

Lexical access is, in itself a complex process that can be even more complex when two languages are involved. If we add a third language to already existing linguistic systems, the complexity of lexical access increases, since there are more sources of influence among the languages. The literature on lexical access offers different models and hypotheses that, under different perspectives, seek to describe and explain the architecture of the bilingual and multilingual mental lexicon (KROLL; STEWART, 1994; DIJKSTRA; VAN HEUVEN, 2002; DIJKSTRA, 2003; DE BOT, 2004).

Among these models, one that has received considerable empirical support (e.g., KROLL et al., 2002; PALMER; VAN HOOFF; HAVELKA, 2010; ALVAREZ; HOLCOMB; GRAINGER, 2003; PHILLIPS et al., 2004; SHOLL; SANKARANARAYANAN; KROLL, 1995) is the Revised Hierarchical Model (RHM) (KROLL; STEWART, 1994), which proposes that there is an asymmetry in the lexical organization of bilinguals. Importantly, the model claims that, for late L2 acquisition, where the L1 lexicon and conceptual memory have already been established, L2 words are added to the system through lexical links with the L1. As proficiency increases, conceptual links for the L2 words are also acquired. However, the lexical connections between L1 and L2 words do not disappear.

One way to investigate lexical access in bilingualism and multilingualism is by means of the semantic priming effect. Semantic priming refers to the facilitation in the processing of a word (the target word) that is preceded by a related word (the prime), comparatively to an unrelated word (PHILLIPS et al., 2004). This facilitation is commonly measured by means of the reaction time in a given task. In cross-linguistic semantic priming, the two languages of the bilingual are present in the 
same task, one language for the target word, and the other for the prime.

The semantic priming effect has been used to investigate a number of issues in L2 and L3 lexical access, including repetition effects within the same language and between two different languages of a bilingual (ALVAREZ; HOLCOMB; GRAINGER, 2003), lexical-semantic activation in a translation task (PALMER; VAN HOOFF; HAVELKA, 2010), the relation between naming pictures and translation (SHOLL; SANKARANARAYANAN; KROLL, 1995), the effects of masked priming translation in simultaneous bilinguals with the same level of proficiency in the two languages (DUÑABEITIA et al., 2010), and the processing of L1 and L2 in semantic categorization (PHILLIPS et al., 2004). Together, the results of studies on semantic priming effects provide support to the view that the words of the L1 and the L2 hold asymmetric relations, as claimed by the RHM.

Aiming at contributing to the discussion regarding the organization of the multilingual lexicon, the present study investigated semantic priming effects in the production of English as L3 by means of a cross-language picture-naming task within the masked priming paradigm. We hypothetized that primes in the target language (English) would be more facilitative in picture naming than primes in the nonnative language (German), which would be more facilitative than primes in the native language (Brazilian Portuguese).

\section{Method}

\subsection{Participants}

The study was carried out with a total of 41 participants, recruited from the area of the UFSC ${ }^{2}$. Participants were assigned to a control group or to one of two experimental groups. The participants of the experimental groups were all native speakers of Brazilian Portuguese, whereas the participants of the control group were 13 native speakers of English. The first experimental group consisted of 12 speakers

${ }^{2}$ The present study was approved by the CEPSH at UFSC. of English as L2 (the L2G). The second experimental group consisted of 16 speakers of German as L2 who were also speakers of English as L3 (the L3G). 
Number of languages mastered and proficiency were controlled for in the recruitment of participants. Therefore, to be included in one of the experimental groups (L2G and L3G), participants should not have knowledge of other languages besides Brazilian Portuguese, German, and English. Proficiency was assessed by means of the Vocabulary Levels Test (PVLT), for English (LAUFER; NATION, 1999), and the test of the Institute for Test Research and Test Development (ITT) for German (this test was developed by the Language Centre of the University of Leipzig on the basis of the frequency list of the Herder/BYU-corpus. The results of the vocabulary test in English for the L2G and the L3G were similar (mean number of correct responses: 14.3 for the L3G, and 15,3 for the $\mathrm{L} 2 \mathrm{G}$ ). On the other hand, for the trilingual participants, there was a higher number of correct items in the German vocabulary test (mean number of correct responses: 21.1) as compared to the English vocabulary test (mean of correct responses: 14.3), suggesting that the participants of the L3G could have a larger vocabulary size in German than in English.

\subsection{The picture-naming task}

The picture-naming task consisted of 72 black and white pictures representing concrete objects (e.g., food, animals, clothes) to be named in English. These pictures were taken from Szekely et al. (2005).

Each picture to be named was preceded by its name in English or its equivalent translation in German, or in Brazilian Portuguese. Therefore, there were 3 experimental conditions in this task:

1. Prime word in the target language (English).

2. Prime word in the native language (Brazilian Portuguese).

3. Prime word in the nonnative language (German).

Since each picture could be presented only once to each participant, there were three presentation lists. For each list, 24 pictures were preceded by its name in English, 24 by its equivalent translation in German, and 24 by its equivalent translation in Brazilian Portuguese. Therefore, each picture was preceded by the prime word in each of the languages across the presentation lists and each participant was exposed to the 
three experimental conditions. This procedure was adopted to make sure that the priming effect would not be due to an effect of the prime and the picture, which could have happened in case the picture to be named were always preceded by the same prime word.

The selection of the pictures included the control of the following aspects: pictures that represented cognate words in the pairs English-Brazilian Portuguese or English-German were eliminated (e.g., dentist). Cognates needed to be avoided because they are well known in the literature to be named faster than non-cognate words. In addition, pictures that represented words that were phonologically or orthographically similar across the languages were also excluded (e.g., cheese was excluded because of its phonological resemblance with the German translation Käse; whale was eliminated since its orthography resembles the equivalent word in German Wal).

The experiment was programmed in the E-Prime v2.0 Professional (Psychology Software Tools, Inc., Sharpsburg, PA, EUA) (SCHNEIDER; ESCHMAN; ZUCCOLOTTO, 2012) software, which registered participants' reaction time, voice, and accuracy for each stimulus. The order of presentation of the stimuli proceeded as illustrated in Figure 1.

Figure 1 - The picture-naming task within the masked priming paradigm.

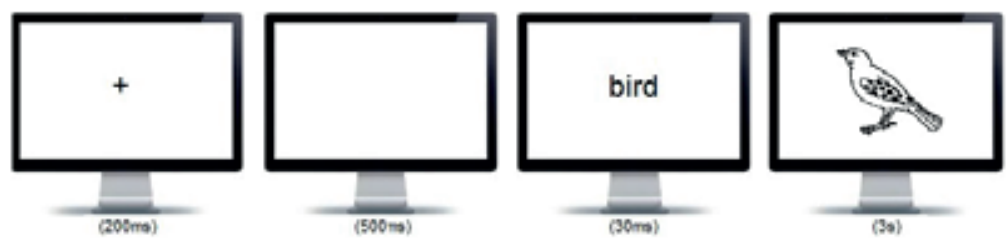

Source: Own authorship.

Figure 1 shows the sequence of presentation of the stimuli in the task. First, a fixation cross appeared in the center of the computer screen for $200 \mathrm{~ms}$, followed by a blank interval of 500 ms. Next, the masked prime was presented for approximately $30 \mathrm{~ms}$, in lowercase, in the center of the computer screen. Immediately after the prime, the picture to be named appeared 
in the center of the computer screen. The picture remained in the computer screen for 3 seconds. The next picture to be named appeared in the screen after an interval of 1s. The task was performed in a DELL XPS 8700 computer, with a Dell 23inch LCD monitor.

Before performing the picture-naming task, participants were required to read and sign an informed consent form. After the picture-naming task, participants answered a questionnaire for biographical information as well as information regarding their background linguistic knowledge. At last, the participants of the experimental groups (L2G and L3G) answered the vocabulary test in English (VLT). In addition, the participants of the L3G answered the vocabulary test in German. Participants of the control group were not required to take any of these tests since they were native speakers of English, the target language of this study.

\section{Results}

The general results of this study are presented in Figure 2, which presents the results of response time of the three groups of participants in the three conditions of this experiment -prime word in English (EN), German (GR) or Brazilian Portuguese (PT).

Figure 2 - Reaction time for the three groups in the three conditions.

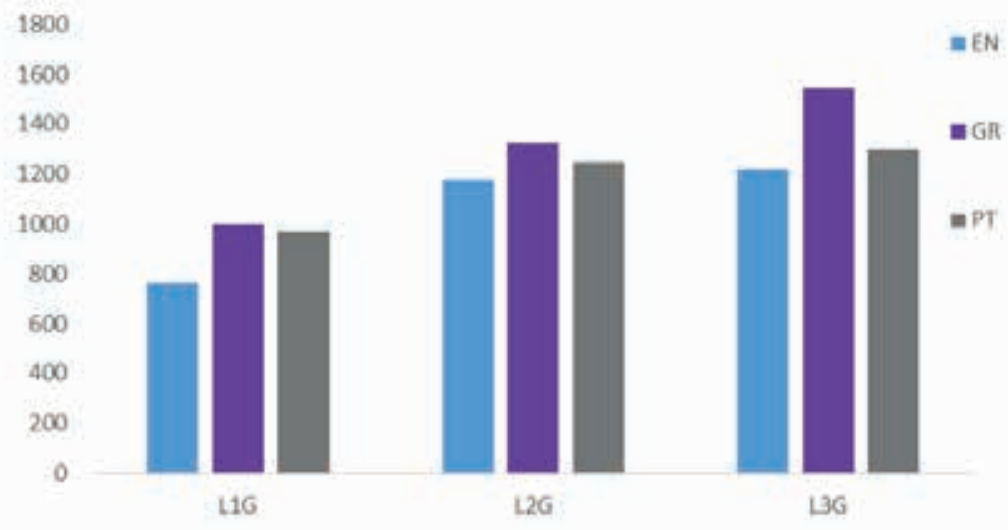

Source: Own authorship. 
Figure 2 shows that the response time of the control group (L1G) was shorter than that of the two experimental groups (L2G and L3G). This result indicates that the design of the present study was adequate, in that it was expected that native speakers of English would name pictures faster than nonnative speakers. Figure 2 also shows that for the L1G, no difference was found in response time when the prime word was presented in German or Brazilian Portuguese, indicating no effect of the prime words in these conditions for the control group. These results indicate that any difference observed in the response time of the participants of the two experimental groups are due to experimental conditions. On the other hand, the results of the control group (L1G) show that the prime word in English apparently caused a faster response, which is an expected result, since the prime word in the target language activates the semantic/conceptual representation of the word as well as its orthographic representation.

Additionally, according to Figure 2, for the three groups, the shortest reaction time occurred when the prime word was presented in English. The prime word presented in Brazilian Portuguese elicited a faster response than when presented in German. It also shows that the behavior of the L2G and L3G was very similar, except for the greater effect observed for the results of the prime word in German for the L3G, which is an expected result, since only the participants of this group were speakers of German. Table 1 provides the descriptive statistics for these data. 
Table 1 - Reaction time for the picture-naming task for the three groups and three conditions

\begin{tabular}{lllll}
\hline PRIME WORD & English & German & $\begin{array}{l}\text { Brazilian } \\
\text { Portuguese }\end{array}$ \\
\hline L1G & Mean (SD) & $759.99(129.00)$ & $1000.88(139.37)$ & $968.81(140.11)$ \\
& Median & 770.25 & 965.78 & 918.73 \\
& Minimum & 526.46 & 858.58 & 779.21 \\
& Maximum & 1048.43 & 1360.59 & 1285.52 \\
L2G & Mean (SD) & $1190.88(313.26)$ & $1323.90(183.03)$ & $1263.63(275.48)$ \\
& Median & 1113.16 & 1311.19 & 1252.15 \\
& Minimum & 839.05 & 1024.12 & 783.47 \\
& Maximum & 1848.33 & 1720.24 & 1822.93 \\
L3G & Mean (SD) & $1217.59(232.37)$ & $1546.05(249.04)$ & $1312.98(220.82)$ \\
& Median & 1155.57 & $156 ., 14$ & 1370.43 \\
& Minimum & 890.80 & 1082.89 & 814.41 \\
& Maximum & 1757.65 & 1929.88 & 1608.05 \\
\hline
\end{tabular}

Note: 41 participants (L1G=13; L2G=12; L3G=16). SD=standard deviation.

Source: Own authorship.

According to the results presented in Table 1, it can be seen that when the prime word was presented in English there was practically no difference between the response time of the participants from the L2G (mean: $1190 \mathrm{~ms}$ ) and the L3G (mean: $1217 \mathrm{~ms}$ ). This result shows that the behavior of the two groups was very similar. Moreover, for the L1G, the prime word in German caused a delay of $241 \mathrm{~ms}$, equivalent to $24 \%$ of the response time (1000 - $759 \mathrm{~ms})$. When the prime word was presented in Brazilian Portuguese, for the L1G, there was a delay of $209 \mathrm{~ms}$ equivalent to $21 \%$ ( $968-759 \mathrm{~ms}$ ) of the reaction time. This difference was slightly smaller than the difference 
between English and German primes. These results show that the reaction time for the control group (L1G) did not differ when the presentation of the prime word was in Brazilian Portuguese or in German. It means that, for the L1G, there was not a large difference between the prime words in the non-target languages.

For the $\mathrm{L} 2 \mathrm{G}$, the presentation of the prime word in English, German or Brazilian Portuguese does not seem to yield large differences in reaction time. On the other hand, for the L3G, an increase of $329 \mathrm{~ms}$ is observed, which corresponds to $21 \%$ (1546-1217ms) of the reaction time when compared to the time spent to name the picture when the prime word was in English or in German. For the L3G, this difference was not so large when the prime word was presented in Portuguese, as compared to English: only $95 \mathrm{~ms}$ longer for the response with the prime word in Brazilian Portuguese.

These results were further submitted to statistical tests. Since the analysis of part of the data showed a non-normal distribution, Wilcoxon test was run to compare the means in each of the groups. Table 2 presents the results of comparisons for the pairs of conditions English-German, German-Brazilian Portuguese and English-Brazilian Portuguese, for the three groups of participants.

Table 2 - Wilcoxon test for the pairs of conditions

\begin{tabular}{lllll}
\hline Group/Condition & & $\begin{array}{l}\text { English- } \\
\text { German }\end{array}$ & $\begin{array}{l}\text { German- } \\
\text { Brazilian } \\
\text { Portuguese }\end{array}$ & $\begin{array}{l}\text { English- } \\
\text { Brazilian } \\
\text { Portuguese }\end{array}$ \\
\hline L1G & Z & -3.180 & -1.293 & -3.180 \\
& Asymp.Sig. (2-tailed) & $0.001^{*}$ & 0.196 & $0.001^{*}$ \\
L2G & Z & -2.040 & -1.726 & -1.569 \\
& Asymp.Sig. (2-tailed) & $0.041^{*}$ & 0.084 & 0.117 \\
\hline L3G & & & \\
& Z & -3.413 & -3.103 & -1.655 \\
& Asymp.Sig. (2-tailed) & $0.001^{*}$ & $0.002^{*}$ & 0.098 \\
\hline
\end{tabular}

Note: 41 participants (L1G=13; L2G=12; L3G=16). * ${ }^{*} p<0.005$.

Source: Own authorship. 
As can be seen in Table 2, the differences of the mean reaction time were significant for all of the groups when the conditions of the prime word in English and German were compared. For the L1G, as expected, when the prime word appeared in English, the response of the native speakers was much faster than when it appeared in German or Brazilian Portuguese. This was confirmed by the significant results of the difference of the means between English and German and between English and Brazilian Portuguese, but not between German and Brazilian Portuguese. It can be assumed that for both the L2 and L3 groups there was some facilitation when the prime word was presented in Brazilian Portuguese, which is confirmed by the absence of a significant difference between the means of the prime in English and Brazilian Portuguese. On the other hand, the response time of the L3G increased considerably when the prime word appeared in German, leading to a statistically significant difference between German and Brazilian Portuguese and between German and English, for this group.

In order to analyze if there were differences in the behavior of the two experimental groups (L2G and L3G), a Mann-Whitney test was carried out. The results are presented in Table 3.

Table 3 - Results of the Mann-Whitney test to compare groups across conditions

\begin{tabular}{lllll}
\hline & & L1G-L2G & L1G-L3G & L2G-L3G \\
\hline English & Z & -4.429 & -0.836 \\
& A s y m p . S i g . & $0.000^{*}$ & $0.000^{*}$ & 0.403 \\
& (2-tailed) & & \\
\hline German & Z & & -2.414 \\
& A s y m p . S i g . & $0.000^{*}$ & $0.000^{*}$ & $0.016^{*}$ \\
& (2-tailed) & & & \\
\hline Brazilian n & Z & & -1.068 \\
Portuguese & A s y m p . S i g . $0.005^{*}$ & $0.001^{*}$ & 0.286 \\
& (2-tailed) & & \\
\hline
\end{tabular}

Note: 41 participants (L1G=13; L2G=12; L3G=16). * = p<0.005.

Source: Own authorship. 
The results of Table 3 confirm the results presented in Table 2 regarding the effect of the second language German for the L3G, which displayed a considerably greater reaction time for this condition. The comparison of the mean reaction time of the L2 and L3 groups when the prime word was presented in German yielded a statistically significant difference, reiterating this effect of the second language. On the other hand, when the prime word was presented either in English or in Brazilian Portuguese the two groups behaved similarly, that is, both groups showed a facilitative effect in these conditions. These results are discussed in the next section.

\section{Discussion}

The results of the present study showed that there was a statistically significant effect of the second language German in the production of English of the trilingual participants, as assessed by means of a picture-naming task within the semantic priming paradigm. This effect was observed by means of a delay in the response time of the trilingual participants when they named pictures preceded by prime words in German. In other words, German interfered in the production of English. When primed in German, the phonological representation of the word in German was activated. Consequently, the name of the picture in German was accessed faster than its translation equivalent in the target language, English. It was necessary to deactivate the second language first, in order to name the picture in English, the participant's third language. This processing cost was reflected in the increase in the response time. This effect did not occur, however, when the prime word was presented in Brazilian Portuguese, the participants' native language, both for the bilinguals and the trilinguals.

There are many tentative explanations for these results. One proposal would be an extension of the assumptions of the RHM (KROLL; STEWART, 1994), in which the links between the native language and the second language would be stronger than the links between the two second languages. In other words, there would be an asymmetry in the lexical organization of the trilingual speaker. This would explain why the prime word in the L1 led to faster access to the conceptual representation of the word to be named, whereas the prime 
word in German caused an increase in response time. In other words, it can be claimed that the strongest connections between the words of the L1 and L3 caused a facilitation in the production of the L3, whereas the weaker connections between words of the L2 and L3 caused an interference in the production of the L3, which was evident in the increase observed in the response time.

Another factor that might have influenced the results of the present study is the context of learning. Since participants of the two experimental groups learned English in the L1 environment (Brazil), it is possible that when they did not know words in English, they resorted to their L1. The same process probably occurred with the learning process of the other second language - German, that is, it can be hypothesized that during the learning process of these two second languages (German and English), the language of reference was always the native language - Brazilian Portuguese. In addition, when learning one of the second languages (German or English), it is possible that few comparisons have been made to the other second language, both from the role of the teacher as of the learner. Therefore, the results of the present study favor the factor of context of learning as influential in the configuration of the mental lexicon. In case these participants had learned the L3 - English in a German-speaking environment, for instance, stronger links between the two foreign languages could have been established.

Therefore, it can be argued that the connections between English and Brazilian Portuguese are stronger than those between English and German, leading to faster response when the prime word was presented in Brazilian Portuguese than in German. Taking into consideration the assumptions of the RHM, it is possible that, with the increase of proficiency, the configuration of the trilingual mental lexicon will be altered; one of the foreign languages may reach a dominance role. In this case, the links from the other two languages (the native and the nonnative) to this foreign language would become stronger.

In short, it can be argued that the results of this experiment support the claim of an asymmetry in the organization of the lexicon of multilinguals. That is, there are probably stronger links between L1-L2, and L1-L3, than between L2-L3. 


\section{Concluding remarks}

In the present study, lexical access in language production was analyzed in a cross-language priming experiment consisting of a picture-naming task where participants had to name 72 pictures that represented concrete objects within a masked priming paradigm. The experiment was designed in such a way as to avoid, as much as possible, the interference of variables such as cognates. In addition, pictures whose names in German and/or Brazilian Portuguese resembled the target one in English, orthographically or phonologically, were excluded of the present study. Therefore, the only aspect to be considered in the analysis of the data is the semantic overlap among the primes and the target. In other words, the focus of this experiment was on the conceptual level of the mental lexicon.

Our results suggest that both the native and the nonnative languages share a common conceptual system. This is confirmed in the results of facilitation and interference reported previously. Nevertheless, the result of interference of the prime word in German as compared to the facilitation of the prime word in Brazilian Portuguese for the trilingual group seems to indicate some difference in the strength of the lexical connections among the native and the nonnative languages. It seems that the lexical links between L1/L2 words and L1/ L3 words are stronger than the lexical links between L2/L3 words. This is an expected result due to the context where this study took place, where participants learned the foreign language in the environment of the L1, as already discussed in the previous paragraph.

Another point that must be taken into consideration is that phonological overlap between prime and target normally causes interference (DIJKSTRA; GRAINGER; VAN HEUVEN, 1999). Even though the present study did not deal with phonological overlap, the results suggest that the prime word in German activated the phonological representation of the word in German, and some extra time was necessary to deactivate this representation, causing an increase in response time. When trying to find the name for the picture, several lexical candidates compete for selection (neighbors). When the prime 
was presented in German, the number of possible candidates increased, leading to a delay in picture naming.

Regarding the research question proposed for this study - Is there a difference in the semantic priming effect when presented in the native (Brazilian Portuguese), nonnative (German) or target language (English) for bilingual and trilingual speakers? - and the hypothesis investigated which stated that the prime word in English would cause a faster response time than the prime word in German, which would cause a faster response time than the prime in Brazilian Portuguese, the results suggest that there is a difference in the priming effect when the prime word is presented in Brazilian Portuguese (the native language), in English (the target language) or in German (the nonnative language). This conclusion is based on the results that showed that the presence of a prime word in German caused a delay in the participants' response. However, the hypothesis was only partially confirmed, since the fastest response times occurred when the prime words were presented in English, than in Brazilian Portuguese, and not in German, as previously predicted.

The processes involved in lexical access in bilingualism and multilingualism are complex. Further research is necessary to increase our understanding of how the lexicons of various languages operate in the service of communication. In the present study, we aimed at contributing to this area of investigation with evidence from native speakers of Brazilian Portuguese, speakers of English as a third language. Our results speak in favor of an integrated lexicon for multilinguals, with an asymmetry in the connections of the words of these languages.

The results of the present study suggest that the lexicons of the native language and the foreign language are more closely connected than the lexicon of the two or more foreign languages a speaker might have. They also confirm the claim that lexical access of multilinguals is qualitatively different from that of bilinguals and monolinguals. These results contribute to the discussion regarding lexical access and the multilingual mental lexicon. 


\section{REFERENCES}

ALVAREZ, R. P.; HOLCOMB, P. J.; GRAINGER, J. Accessing word meaning in two languages: An event-related brain potential study of beginning bilinguals. Brain and Language, v.87, n.2, p. 290-304, 2003.

DE BOT, K. The multilingual lexicon: Modelling selection and control. International Journal of Multilingualism, v.1, p.17-32, 2004.

DIJKSTRA, T. Lexical processing in bilinguals and multilinguals. In: CENOZ, J.; HUFEISEN, B.; JESSNER U. (Ed.). The multilingual lexicon. New York: Kluwer Academic Publishers, 2003, pp 11-26.

DIJKSTRA, T.; GRAINGER, J.; VAN HEUVEN, W. J. Recognition of cognates and interlingual homographs: The neglected role of phonology. Journal of Memory and language, v.41, n.4, p. 496$518,1999$.

DIJKSTRA, T.; VAN HEUVEN, W. J. B. The architecture of the bilingual word recognition system: from identification to decision. Bilingualism: Language and Cognition, v.5, n.3, p. 175197, 2002.

DUÑABEITIA, J. A. et al. Electrophysiological correlates of the masked translation priming effect with highly proficient simultaneous bilinguals. Brain research, v.1359, p. 142-154, 2010.

ECKE, P. Parasitic vocabulary acquisition, cross-linguistic influence, and lexical retrieval in multilinguals. Bilingualism: Language and Cognition,v.18, n.2, 201, p. 1-18.

HAMMARBERG, B. Roles of L1 and L2 in L3 production and acquisition. In: CENOZ, J.; HUFEISEN, B.; JESSNER $\mathrm{U}$ (Ed.), Cross-linguistic influence in third language acquisition: psycholinguistic perspectives. Clevedon: Multilingual Matters, 2001, pp. 21-41.

HARTSUIKER, R. J. et al., Cross-linguistic structural priming in multilinguals: further evidence for shared syntax. Journal of Memory and Language, v.90, p. 14-30, 2016. 
JESSNER, U. The nature of cross-linguistic interaction in the multilingual system. In: CENOZ, J.; HUFEISEN, B.; JESSNER, U. (Ed.). The multilingual lexicon. New York: Kluwer Academic Publishers, 2003, pp 45-56.

KROLL, J. F.; STEWART, E. Category interference in translation and picture naming: Evidence for asymmetric connections between bilingual memory representations. Journal of memory and language, v.33, n.2, p. 149-174, 1994.

KROLL, J. F. et al. The development of lexical fluency in a second language. Second language research, v.18, n.2, p.137-171, 2002.

KROLL, J. F. Accessing conceptual representations for words in a second language. In: SCHREUDER, R.; WELTENS, B. (Ed.), The Bilingual Lexicon. Amsterdam: John Benjamins, 1993, p. 53-81.

LAUFER, B.; NATION, P. A vocabulary-size test of controlled productive ability. Language testing, v.16, n.1, p. 33-51, 1999.

LEUNG, Y. I. Second versus third language acquisition of tense and agreement in French by Vietnamese monolinguals and Cantonese-English bilinguals. In: ISB4: Proceedings of the 4th International Symposium on Bilingualism. Sommerville, MA: Cascadilla Press, 2005. p. 1344-1352.

PALMER, S. D.; VAN HOOFF, J. C.; HAVELKA, J. Language representation and processing in fluent bilinguals: Electrophysiological evidence for asymmetric mapping in bilingual memory. Neuropsychologia, v.48, n.5, p.1426-1437, 2010.

PHILLIPS, N. A. et al. Semantic priming in a first and second language: evidence from reaction time variability and eventrelated brain potentials. Journal of Neurolinguistics, v.17, n.2, p. 237-262, 2004.

SCHNEIDER, W.; ESCHMAN, A.; ZUCCOLOTTO, A. E-Prime 2.0 reference guide manual. Pittsburgh, PA: Psychology Software Tools, 2012. 
SHOLL, A.; SANKARANARAYANAN, A.; KROLL, J. F. Transfer between picture naming and translation: A test of asymmetries in bilingual memory. Psychological Science, v.6, n.1, p. 45-49, 1995.

SOUZA, R. A. Two languages in one mind and the online processing of causatives with manner-of-motion verbs. ReVEL, special issue, v.6, p. 220-239, 2012.

SOUZA, R. A. D.; OLIVEIRA, F. L. P. D. Is knowledge of a nondominant L2 activated by bilinguals using their dominant L1? Insights from an on-line psycholinguistic study. Organon, v.26, n. 51, p. 103-126, 2011.

SZEKELY, A. et al. Timed action and object naming. Cortex, v.41, n.1, p. 7-25, 2005.

SZUBKO-SITAREK, W. Multilingual lexicon recognition in the mental lexicon of third language users. Heidelberg: Springer, 2015.

VINNITSKAYA, I.; FLYNN, S.; FOLEY, C. The acquisition of relative clauses in a third language: comparing adults and children. Proceedings of the 6th Generative Approaches to Second Language Acquisition Conference, Cascadilla Proceedings Project: USA, 2003, p. 340-345. 


\section{Abstract \\ Efeitos de priming semântico e acesso lexical em inglês como L3}

Reporta-se, neste artigo, os resultados de um experimento que investigou o acesso lexical em inglês como terceira língua por meio de uma tarefa de nomeação de figuras no paradigma de priming mascarado. Os participantes foram organizados em três grupos: um grupo controle, formado por falantes nativos de inglês, e dois grupos experimentais, sendo um formado por falantes de inglês como L2 e o outro, por falantes de inglês como L2 e de alemão como L3. Todos os participantes desempenharam uma tarefa de nomeação de figuras em que estas eram precedidas por palavras prime em inglês (a lingua alvo), português brasileiro (a lingua nativa), ou alemão (a segunda língua). Os resultados indicam alguma interferência da segunda lingua desses participantes na produção da terceira lingua e favorecem a visão de que o acesso lexical de multilingues é qualitativamente diferente daquele de bilingues e monolingues.

Palavras-chave: acesso lexical, multilingues, efeito de priming, tarefa de nomeação de figuras. 